of us who do not live in tenement houses or hotels occupy houses mortgaged to the limit. These mortgages we never intend to pay. When we need a new or better automobile, we not infrequently obtain the money for it by placing a second mortgage on our homes at a higher rate of interest. Let not Dr. Diller quote the aphorisms of Poor Richard on Manhattan Island. Nous avons changé tout cela!

Probably the most remarkable and original contribution of Franklin to medicine was his early recognition of the value of fresh air in health and disease. His campaign for the most part, however, fell on deaf ears. His contemporaries were a stiff-necked generation, and in their fear of drafts they almost unanimously approved the sentiment contained in the old couplet:

When the wind blows through a hole,
May God have mercy on your soul!

Henry L. Shively, M.D., New York.

\section{Auricular Fibrillation and Pulsus Alternans}

To the Editor:-Dr. Harold E. B. Pardee (The Prognosis of Auricular Fibrillation, The Journal, June 19, 1915, p. 2057) uses the following phrase in his concluding sentence: "the irregularity, per se, adds little or nothing to the gravity of the prognosis." According to Lewis, the irregularity of the pulse of auricular fibrillation is the most common of the seven different varieties of arrhythmic pulse, and, of course, one of the gravest. irregularity of the pulse which cannot be detected without the use of tracings or the electrocardiograph.

I can confirm all that Drs. Herrick and McGill say about the usefulness and simplicity of the method, since I have employed it for about a year in many cases. This irregularity is commoner than supposed, and can be detected without complicated apparatus.

No one with pulsus alternans can endure a major operation, as the condition is always grave and the patient is constantly in jeopardy. Merely palpating the radial artery and listening to the heart will not make the diagnosis. The pulse may be strong, the heart beats forcible and regular to the ear, and yet an operation will be followed by disastrous results.

By blocking off all the beats in the radial artery by inflating the cuff on the arm and then by deflation slowly, only the strong beats come through to the radial, while the weak ones are still blocked off; halving of the pulse rate, previously counted, permits making a diagnosis. The method is simple and should be employed by all clinicians.

Dr. Herrick might have mentioned that pulsus alternans cannot always be found in one, subject to this complaint. The alternations follow an extrasystole or are produced by exercise. This irregularity is often found with high blood pressure, angina pectoris, nocturnal asthma and CheyneStokes respiration.

In 1905, Dr. James Mackenzie noted pulsus alternans in a man, and made a tracing of his pulse; by using the cuff in the method described by Dr. Herrick, he was able to block

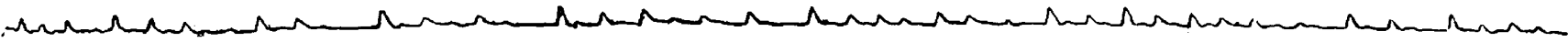

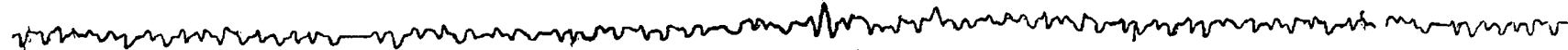

Tracing in a case of arrhythmia.

That the irregularity, per se, has nothing to do with the prognosis is well exemplified in the following case: A man, aged 58 , has had this type of irregular pulse since he was 33. He has no valve lesion, dilatation or other muscle disease or weakness; he has had no dyspnea or decompensation. There is no history of infectious disease, such as rheumatism, which might damage the conductivity and integrity of his heart muscle. Three times he was passed in life insurance examination by competent doctors. For years he suffered from chronic diarrhea. $\mathrm{He}$ is thin and spare, but is very active and in good health. His pulse rate is generally above 80 , always irregular; there is always pulse deficiency, the apex beat being more frequent than the radial pulse. For years he was a surveyor and was able to climb mountains, carrying instruments, and suffered no discomfort. Since his type of irregularity conforms to but one form of the seven various kinds, and that auricular fibrillation, it must be this from the character of the tracing herewith shown.

Since he has never taken digitalis, it is impossible to say whether this drug could sufficiently dominate. (depress) the conductivity of the bundle of $\mathrm{His}$, so as to render the pulse regular.

In some ways this perpetual arrhythmia corresponds to Mackenzie's rhythm, a form of irregularity no longer considered a distinct variety of arrhythmia by Lewis.

Dr. Caroline McGill (The Determination of Pulsus Alternans by the Sphygmomanometer, The Journat, June 19, 1915 , p. 2061) rightly credits Dr. J. B. Herrick with the discovery of this valuable clinical test.

The prognosis of pulsus alternans is always grave in cases of myocarditis, and Lewis states that that is the only form of off the weak beats and allow the strong ones to be registered by the tambour. This is well shown on page 405 of the third edition of his book.

Mackenzie makes no mention of the practical bedside detection of pulsus alternans by the auscultation of the brachial or palpation of the radial, using the cuff, as employed by Dr. Herrick, and to the latter belongs the credit of directing the attention of the profession to this test.

The fact that fibrillation of the auricle exists is not itself sufficient to prevent a major operation. Recently Dr. John B. Deaver removed the half of an exophthalmic goiter in a woman who had suffered from fibrillation for years and with chronic nephritis, very successfully and with much benefit to the patient.

Robert L. Pitfield, M.D., Philadelphia.

\section{Public Menaces}

To the Editor:-I was interested in the communication (The Journal, July 17, 1915, p. 272) concerning the cigar cutter. There is another public menace which ought to be called attention to, and that is the use of the hand lever commonly seen in public urinals. This lever is used to flush the bowl. Above the lever are the words, "Please push down after using." A person with gonorrhea, after handling the penis during micturition, pushes down on the lever with the same hand that held the infected penis. Thus, during a short period of time, many persons are needlessly exposed, unless they are aware of the danger and act accordingly.

Frank E. Lewis, M.D., Newton, Mass. 